\title{
The Impact of Adaptive Preferences on Subjective Indicators: An Analysis of Poverty Indicators
}

\author{
Eric Crettaz $\cdot$ Christian Suter
}

Accepted: 30 June 2013/Published online: 2 August 2013

(C) Springer Science+Business Media Dordrecht 2013

\begin{abstract}
Subjective indicators are often criticized since they are thought to be particularly affected by the phenomenon of adaptive preferences and social comparison. For social policy purposes, processes of downward adaptation in disadvantaged individuals are of particular importance, i.e., it is supposed that such people compare themselves with others who are in the same precarious situation or even worse off and, as a result, lower their expectations and adapt their aspirations and preferences to their material and financial constraints. Based on the 2006-2010 waves of the Swiss Household Panel study, this contribution examines whether, and to what degree, indicators of material deprivation, subjective poverty and subjective well-being are affected by such downward adaptations. Our empirical analysis demonstrates that the bias caused by adaptation processes varies considerably among different measures and that, although subjective indicators are indeed often affected by this phenomenon, there are also robust measures, notably Townsend's deprivation measure, Halleröd's proportional deprivation index and the subjective wellbeing measure of general life satisfaction.
\end{abstract}

Keywords Adaptive preferences - Downward adaptation - Social comparison · Subjective indicators $\cdot$ Poverty $\cdot$ Deprivation $\cdot$ Well-being

\footnotetext{
E. Crettaz $(\bowtie)$

Center for the Understanding of Social Processes (MAPS), University of Neuchâtel, Faubourg de l'Hôpital 27, 2000 Neuchâtel, Switzerland

e-mail: eric.crettaz@unine.ch

C. Suter

Department of Sociology, University of Neuchâtel, Faubourg de 1'Hôpital 27,

2000 Neuchâtel, Switzerland

e-mail: christian.suter@unine.ch
} 


\section{Introduction}

Subjective indicators are increasingly used for measuring and evaluating quality of life and social progress and for assessing the success or failure of related policy measures and programs. In Europe, poverty indicators are particularly affected by this development. Thus, in the wake of the European Union's (EU) Lisbon and the 2020 strategies the traditionally used monetary, income-based poverty indicators have been increasingly complemented by more subjective measures, like deprivation indicators or the perception of financial constraints. In a similar vein, the Stiglitz report (Stiglitz et al. 2009) stressed the importance of developing alternative, noneconomic and subjective measures of social progress.

Critics of subjective indicators, however, point to the well-known phenomenon of adaptation mechanisms and social comparison processes, namely, that individuals' subjective downward assessment of their living conditions are influenced by, and adapted to, their expectations. For social policy, adaptation processes in disadvantaged individuals are of particular importance, since it is supposed that such people adapt to their precarious situation due to downward comparisons: they compare themselves with others who are in the same precarious situation or even worse off; as a result, they lower their expectations and adapt their aspirations and preferences to their material and financial constraints.

There are good reasons to suspect that subjective indicators dealing with the issues of "poverty" and "social exclusion" could be particularly affected by poor people's subconscious adjustments to their material situation. As Sen (1984: 309) put it three decades ago "the underdog learns to bear the burden so well that he or she overlooks the burden itself." Obviously, the traditional income poverty indicators are much less affected, since they are based on factual elements (wages and salaries, taxes and benefits, household size and composition, etc.). Sure enough, some respondents may misreport their earnings and incomes, but these factual elements are not subject to interpretations. On the contrary, indicators of material deprivation, that is, the poverty indicators that have been proposed to circumvent the well-known limitations of income-based measures (poverty goes beyond financial issues and income misreporting in surveys is a nontrivial issue) are more likely to be affected. This is the case with indicators of nonmonetary material deprivation, since these indicators include both a factual element - whether a household possesses an item or not-and a subjective assessment-is not having an item a choice or is it due to lacking financial resources? We argue that this preference question in particular is prone to downward adaptation. Furthermore, the adaptation problem is very likely to be even more marked for purely subjective poverty indicators like the question pertaining to the income deemed necessary to make ends meet, i.e., the "minimum income question" or subjective well-being and satisfaction measures.

Although the issues of adaptation mechanisms and social comparison processes have been raised and debated since the 1960s and 1970s, empirical evidence on how exactly the quality of life and poverty indicators are affected by these processes is still surprisingly scarce. This might be attributed to the demanding and high quality data necessary for dealing with these questions. Thus, panel data are needed, in order to assess whether or not respondents (subconsciously) adjust their preferences to their material situation, and whether or not this impacts on the evaluation of their own financial situation, hence "distorting" the researcher's conclusions.

The main purpose of this contribution is to analyze the impact that previous poverty spells-defined in income terms - have on nonmonetary material deprivation indicators and on various indicators of subjective poverty and subjective well-being. In order to 
assess this phenomenon in a dynamic way, our analysis will be based on the data of the Swiss Household Panel study (SHP). The SHP has the advantage of containing the necessary variables to assess whether a person is income poor and/or materially deprived, as well as a wide range of subjective indicators.

\section{Subjective Indicators and Adaptation Processes: Theoretical Perspectives}

There is a vast amount of literature in the social sciences dealing with the phenomenon of adaptation and of comparing oneself with relevant others. More than 50 years ago Festinger (1954) formulated his similarity hypothesis suggesting that individuals compare themselves to others on the basis of similarity. This argument has been developed further by Runciman (1966) and others who conceptualized individuals' dissatisfaction and discontent, resulting from comparing their lot with that of similar relevant others, as relative deprivation that negatively impacts on social and political stability. Subsequent research has shown that the mechanisms of referencing one's own situation to that of others and the effects are more complex. Two theoretical strands are of particular interest in the context of our study: Firstly, the concept of material deprivation based on the pioneering work of Townsend (1979) which resulted in the subjective poverty and nonmonetary deprivation indicators currently published in the official EU and The Organization for Economic Co-operation and Development (OECD) statistics (Boarini and Mira d'Ercole 2006; OECD 2008) and, secondly, adaptation theory developed in the context of quality of life research in order to explain the weak relationship between objective living conditions and subjective well-being (Brickman and Campbell 1971; Easterlin 1974).

\subsection{Relative Deprivation Theory}

In his seminal study on poverty in the United Kingdom, Townsend (1979) demonstrated that income-based monetary indicators of poverty and nonmonetary indicators of material deprivation are complementary rather than substitutive. Townsend's concept of relative deprivation explicitly concerns social comparison processes, since the goods, services and activities included in his deprivation list refer to a minimum standard of living considered as necessary to lead a decent life in a given society. Townsend's (1979) study generated manifold comments, criticism and further research, notably in the context of research on poverty and social exclusion in Europe, leading to more refined concepts, indicators and analyses. The validity and reliability of deprivation items and measures in particular has been widely debated. Indeed, Townsend selected his deprivation items rather arbitrarily; his deprivation measure was based on all lacking items, i.e., without taking into account individual preferences or financial constraints and without linking lacking items to necessities. Subsequent research (Boarini and Mira d'Ercole 2006; Halleröd 1995; Mack and Lansley 1985; Nolan and Whelan 2010; OECD 2008) has led to a large consensus on deprivation list characteristics and on the importance of asking respondents whether they do not have a specific item due to financial reasons ("cannot afford") or due to other reasons (i.e., personal preferences), as well as on the fact that poverty is more than a low income (Gazareth and Suter 2010; Halleröd 2006). Researchers however are still divided on the question of deprivation measures and index construction: simple binary scores or simple unweighted summary measures have been used, but also weighted measures as well as synthetic indices based on latent variable models (e.g., Halleröd 1995; Nolan and Whelan 2007; OECD 2008). Despite this long tradition, indicators of material deprivation 
made their way into official statistics only after the enlargement of the EU, when the validity of relative poverty lines (a percentage of median income) for comparing various countries with large differences in terms of economic development was called into question.

Closely related to the issue of deprivation measurements is the problem of adaptive preferences, i.e., the distinction between individual preferences, financial constraints, and the adaptation of preferences to financial constraints. Although survey questions on deprivation have been refined, the problem of adaptive preferences is still present, as demonstrated by Halleröd's (2006) analysis of Swedish data. Based on recent own research (Crettaz 2012) we hypothesize that the question of financial constraints in particular is associated with adaptation processes, i.e., that poor households who lack an item for many years are more likely to say that it is by choice rather than because of lacking financial resources.

\subsection{Adaptation Theory}

Adaptation theory deals with the weak correlation of objective and subjective indicators of well-being, i.e., the phenomenon that improvements in objective living conditions often lead to only temporary and/or small increases in subjective well-being and general life satisfaction. In his pioneering work Easterlin (1974) explained the paradox of rising income and stable life satisfaction by rising aspiration levels. Other authors attribute the weak relationship between changes in objective living conditions and subjective perceptions to homeostatic processes, i.e., that the well-being of individuals (and societies) is characterized by a relative stable baseline (Diener et al. 2006; Lucas et al. 2003). Certain events may increase subjective well-being (e.g., lottery winnings) or decrease it (e.g., unemployment, poverty), but after a certain adaptation period it returns to its (individual) baseline. According to this view, repeated events or stable circumstances (favorable or unfavorable) are particularly associated with adaptation processes. We therefore hypothesize that individuals permanently experiencing poverty get more adapted to their precarious situation and thus tend to be more satisfied than individuals who have been confronted with poverty only temporarily.

\section{Data, Indicators and Methodology}

\subsection{Data Set and Sample}

Our empirical analysis is based on the SHP which has been carried out in Switzerland since 1999 (see www.swisspanel.ch for more details on the SHP survey). In this contribution we focus on the 5-year period from 2006 to 2010 . We decided to limit our analysis to 5 years for methodological reasons. As the income poverty risk is, luckily, limited to a relatively small share of the Swiss population-14.2\% in 2010 according to official statistics (Swiss Federal Statistical Office 2012), and because many poverty spells are of a relatively short duration, a longer time period would have meant that the number of cases would have been too small to be statistically reliable. For this 5-year period, we were able to include more than 1,300 persons in each of the models presented below.

For methodological reasons we decided to confine our sample to respondents who have Swiss citizenship and who were born in Switzerland. The main reason for this limitation is that foreigners are strongly underrepresented in the SHP, since the survey is conducted in 
the official national languages only. Unfortunately, the resulting biases cannot be corrected by weighting. Moreover, due to its cultural diversity and the long history of immigration, the foreign-born population is very heterogeneous in Switzerland, which complicates the statistical analysis for controlling for cultural and migration-specific effects.

\subsection{Measures and Indicators}

Given the purpose at hand in this contribution, the first step to be taken is to assess whether a respondent lives in a household that has experienced a period of income poverty in the recent past, that is, over the 5-year period preceding the last interview in 2010. Hence, in each year between 2006 and 2010, the household's yearly equivalized disposable income was calculated, that is, the after-tax (income tax and social security contributions) income standardized with an equivalence scale, so that the income levels of households with different sizes and compositions can be compared, namely the so-called modified OECD scale. It has been shown elsewhere that both the income and the tax variables contained in the SHP dataset are reliable (Crettaz 2012). In order to assess the poverty status of a household, the official at-risk-of-poverty line of the EU has been used, namely $60 \%$ of median disposable equivalized income. The poverty risk is distributed as follows: $76.9 \%$ of respondents were never poor between 2006 and 2010, $12.6 \%$ in 1 year only, $4 \%$ in 2 years, $2.7 \%$ in 3 years, $1.9 \%$ in 4 years, and $1.8 \%$ over the entire 5-year period.

This indicator is the main variable of interest in this contribution, as it is hypothesized that, if the phenomenon of adaptive preferences exists, persons who experience financial difficulties over a certain period of time adjust their preferences to the material situation, which should be reflected in their perception of their financial situation at the end of the 5 -year period. This phenomenon is also supposed to have an impact on indicators of material deprivation: on the one hand, they are based on factual elements-whether or not households lack certain goods, have financial difficulties, or do not have access to given services. On the other hand, they also contain a subjective assessment: if a respondent lacks an item, he or she must say if this is so because he or she cannot afford it, or if it is by choice. If the phenomenon of adaptive preferences exists, or likewise if homeostatic processes are at play, disadvantaged persons might end up preferring the goods they can afford and have the feeling that they have "chosen" not to buy the more expensive ones.

In the analyses presented below, we control for other variables that, according to the literature, may also have an impact on material deprivation and the various subjective measures of the respondents' perceptions of their financial situation and well-being (cf. Suter and Iglesias 2005). The income level at the time of the last interview is obviously an important factor; in the models presented below we use the logarithm of the households' equivalized disposable income. In addition, educational level (split into three broad categories, namely, compulsory schooling, vocational training and other secondary educational paths, and higher/tertiary education), gender, and household size and composition (the number of children under 18 years of age and number of adults in the household), and the employment situation are included.

Let us now move on to describing the dependent variables analyzed in this article. In what follows, we will use an indicator of material deprivation that is as close as possible to the official EU indicator. The number of lacking items is simply added up, and a household that cannot afford three or more items is classified as materially deprived. As already mentioned, indicators of material deprivation can also be conceptualized relative to society's standard of living, by using a weighting scheme. 
The list of items advocated by Eurostat is the following: arrears on mortgage or rent payments, arrears on utility bills, arrears on hire purchase installments or other loan payments, capacity to afford 1 week's annual holiday away from home, capacity to afford a meal with meat, chicken, fish (or vegetarian equivalent) every second day, capacity to deal with unexpected financial expenses, having a telephone (including mobile phone), a color TV, a car, a washing machine, ability to keep the home adequately warm. The three indicators pertaining to arrears of payment are then collapsed into one category. These variables are collected in the survey of income and living conditions (SILC) that is carried out in all EU member states as well as in Switzerland. However, at the time of writing this article, the number of waves collected in Switzerland is too limited to carry out a valid longitudinal analysis; that is why we chose to use the SHP data instead. Eight of the nine items used by Eurostat are also found in the SHP (two of which use a slightly different formulation). Only one item really poses a problem as to comparability, namely, the capacity to afford a meal with meat, chicken, fish (or vegetarian equivalent) every second day: this question is not asked in the SHP, and no similar question is available. The one that is closest concerns having a meal at a restaurant at least once a month; although this item also pertains to food consumption, it differs in the degree of deprivation it implies. However, for the purpose at hand here, it is very unlikely to distort conclusions in terms of adaptive preferences.

For this indicator, four aspects will be closely looked at: the odds of not being able to afford at least three out of the nine items (model 2 in Table 1, "Appendix"), the odds of not being able to afford a higher number of items (model 3 in Table 1, "Appendix"), the odds of lacking an item, regardless of the reason (model 4 in Table 1, "Appendix"). Then, the propensity of saying "I cannot afford it" will be analyzed, by measuring the odds of being materially deprived (not being able to afford at least three out of the nine items) when controlling for the number of missing items (model 1 in Table 1, "Appendix").

Concerning the relative approach to the construction of a deprivation index, we decided to use the Proportional Deprivation Index (model 5 in Table 1, "Appendix"), a measure first developed by Halleröd (1994) which has also been used in the Swiss context (Gazareth and Suter 2010; Suter and Iglesias 2005). The Proportional Deprivation Index (hereafter PDI) is also based on a list of items, but each item is given a weight that equals the proportion of the population identifying it as a necessity. That is, the higher the percentage of respondents who think that an item is necessary to lead a decent life, the higher the weight that is ascribed to this indicator. More specifically, for a list of $\mathrm{j}$ items, for household $i$, the level of deprivation is calculated as follows $\sum_{j=1}^{J} w_{j} d_{j}$, with $w_{j}$ the percentage of respondents who think that item $\mathrm{j}$ is absolutely necessary to lead a decent life and $d_{j}$ a dichotomous variable that takes a value of 1 if the household cannot afford item $j$. The PDI is, hence, the weighted sum of the number of items a household cannot afford. The version we present is standardized so that it ranges from 0 to 100 ; in our sample it ranges from 0 to 86.15 .

It is noteworthy that the list of items used for the construction of the PDI (Gazareth and Suter 2010) is different from the one presented above. Some items are common to both lists: having a color TV, a car, a washing machine, being able to eat at a restaurant at least once a month and to take a week's holiday away from home. Other variables are included, namely, having a dishwasher and a computer, being able to save money in a private pension fund, and being able to invite friends to one's home at least once a month. Therefore, a sensitivity analysis will be carried out by using this list of items to construct the Eurostat-type indicator, as analyzed below. The information regarding the importance 
that the general population attributes to each item included in the list does not stem from the SHP; it is taken from a one-off survey that was carried out in many European countries, including Switzerland, in 1999/2000, namely the Euromodule survey (Suter and Paris 2002). Though these data are relatively dated, it is quite unlikely that preferences have massively changed over a decade, with the notable exception of computers.

Finally, purely subjective indicators will also be looked at, most of which deal with the perception of the household's material and financial situation. Two questions deal with the degree of satisfaction with household income and with one's own financial situation, one deals with the difficulty to make ends meet, and one is the famous "minimum income question", that is, the amount of money deemed necessary to make ends meet, which has been widely used by advocates of subjective poverty lines (Crettaz 2011; van Praag et al. 1980). Finally, we also included a measure of satisfaction with life in general, as it plays such an important role in happiness and quality of life research.

\subsection{Methods of Data Analysis}

To analyze the data we use various types of regression models. Given the nature of our dependent variables (two dichotomous variables, six polytomous ordinal variables, two quantitative variables), we have used logistic regression models, multinomial logistic models, a standard OLS model, and finally a weighted least square model for the PDI, as preliminary models showed that there was a significant heteroskedasticity problem, with predictions being worse, the higher the PDI.

The main goal of our models is to answer the following question: all else being equal (household disposable income at the end of the period, educational level, employment status, gender, household size and composition), what is the impact of an additional year spent on low income on the indicators described above? If we are right in assuming the existence of adaptive preferences, then an additional year spent in poverty may have counterintuitive impacts, such as increasing satisfaction or reducing material deprivation.

\section{Results}

Let us start by analyzing the phenomenon of adaptive preferences from the perspective of relative deprivation, by taking a closer look at indicators of material deprivation (both the Eurostat-like indicators and the PDI). Table 1 (see Appendix) presents five models: model 1 predicts the odds of lacking three or more items because of limited financial resources controlling for the number of items not possessed-thereby assessing the tendency to blame the nonpossession of an item on low income. Model 2 predicts material deprivation as defined by the EU (that is, a dichotomous variable indicating whether a household cannot afford three or more items). Model 3 measures the odds of a household not being able to afford an increased number of items, i.e., without setting a deprivation threshold. Model 4 predicts the number of lacking items, whatever the reason-which was the original approach advocated by Townsend (1979)—while the last model predicts the level of the PDI, that is, the deprivation index that is weighted according to the importance attributed to each item by the general population.

In order to present results in an intuitive manner, Fig. 1 graphically represents adaptation mechanisms, namely the impact on indicators of material deprivation of one, three, and 5 year(s) spent in income poverty, over the 5-year period analyzed here. Figure 1 is based on the regression coefficients obtained from regression models that control for 
Model 1: Odds of blaming lack of items on financial resources (No. of lacking items controlled for)

Model 2: Odds of lacking items due to financial reasons (unweighted sum of items, Eurostat-like indicator )

Model 3: Odds of lacking more items due to financial reasons

Model 4: Odds of lacking more items, whatever the reason

Model 5: Proportional deprivation index (weighted sum as a function of social importance of items, value 0-100)

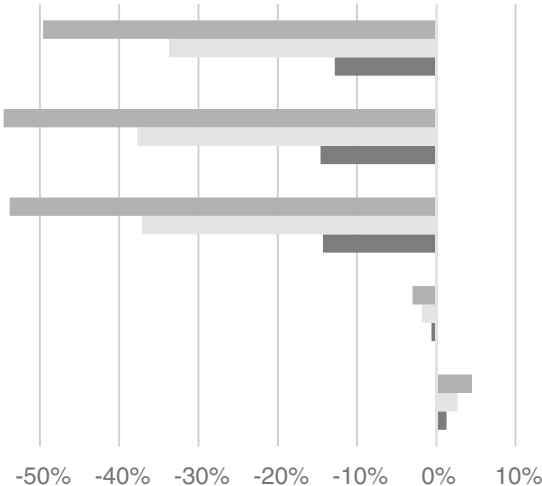

$\square$ years in poverty $\quad 3$ years in poverty 1 year in poverty

Fig. 1 Impact of 1/3/5 years spent in income poverty on indicators of material deprivation (variation in percent). Income poverty defined as below $60 \%$ of the median of equivalized disposable household income. For the PDI: case of a person who was poor in the first year and had a PDI of 13. All effects are statistically significant. Detailed results for all models are presented in Table 1 of the "Appendix". Source: Swiss Household Panel 2006-2010, authors' computations

income level, gender, education, household size and composition, age, and employment status. Detailed results (all coefficients, significance tests, $\mathrm{R}^{2}$ and pseudo- $\mathrm{R}^{2}$, number of cases) are presented in Table 1 in the "Appendix".

We focus here on our variable of interest, that is, the number of years during which household disposable income was below the EU's official at-risk-of-poverty line. Results are striking: controlling for income and educational level, employment status and several sociodemographic variables, the first model indicates that an additional year in which relative poverty was experienced reduces the odds that a respondent says "I cannot afford it" when he or she lacks an item. Moreover, the impact is quite large, as the odds decrease by $12.8 \%$; after 5 years the odds are cut in half. The second model shows that Eurostat's indicator-or, at least, a very similar version-also seems to reflect the existence of adaptive preferences: an additional year spent in poverty decreases the odds of being materially deprived by $14.6 \%$, while the odds of not being able to afford more items go down by $14.3 \%$ (third model). Here too, 5-year effects are marked (around -55 and $-54 \%$ respectively). However, it is noteworthy that when the subjective component is removed, the number of years in poverty hardly has an impact (see model 4). Another interesting result is found in Fig. 1, model 5: the PDI, that is, the sum of lacking items that is weighted on the basis of the percentage of the population that deems an item to be necessary to lead a decent life, does not seem to be "affected" by the phenomenon of adaptive preferences. Indeed, each additional year spent in poverty increases the PDI by 0.177 (see Table 1, "Appendix"); e.g., for a person who was poor and had a PDI of 13 in the first year (we chose this value because it is the mean PDI among the income poor population in 2010), this corresponds to a $1.4 \%$ increase after 1 year and to $4.5 \%$ after 5 years (model 5 in Fig. 1). This increase is small in magnitude; however, it is remarkable that over a 5-year period this indicator shows the consistently negative impact of poverty spells. Moreover, this is not attributable to the fact that this indicator is based on a slightly different items list: a sensitivity analysis was carried out by calculating the Eurostat-style indicator with the items used to calculate the PDI and, in this case, each additional year 


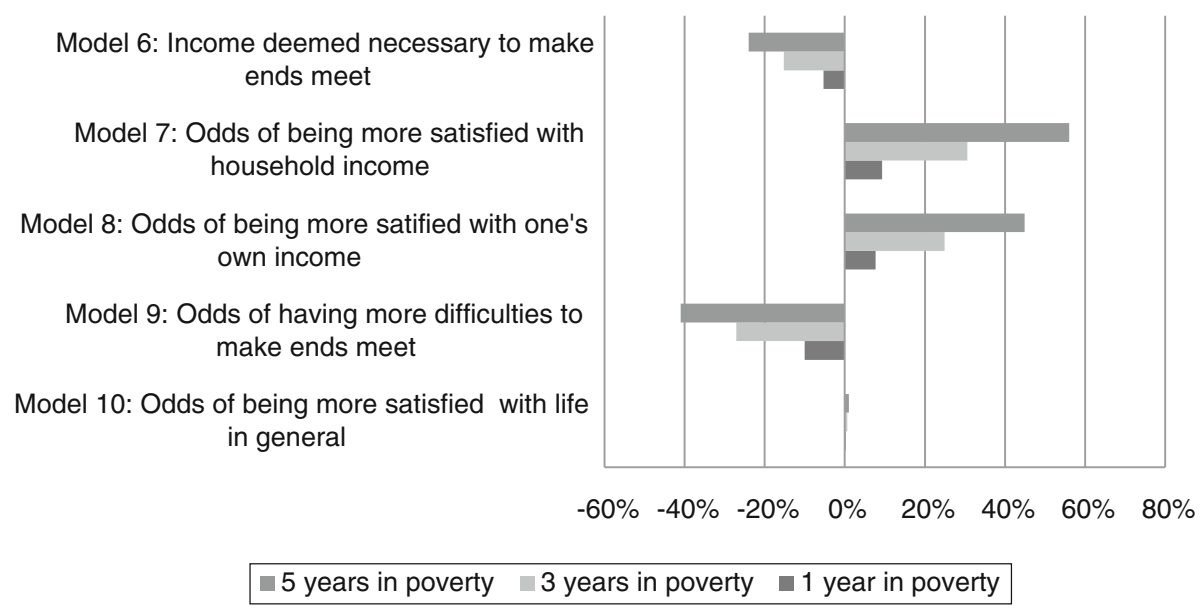

Fig. 2 Impact of 1/3/5 years spent in income poverty on various subjective indicators related to the income satisfaction and on the overall level of satisfaction (variation in percent). Income poverty defined as below $60 \%$ of the median of equivalized disposable household income. Effects are not significant in model 10; all other effects are statistically significant. Detailed results for all models are presented in Table 2 of the “Appendix". Source: Swiss Household Panel 2006-2010, authors' computations

spent in poverty reduces the odds of being materially deprived (regression model not shown here). Hence, this notable change in the direction of the impact of poverty spells appears to be attributable to the weighting scheme.

Having now assessed the impact of previous poverty spells on indicators of material deprivation, we can analyze the issue of the adjustment of preferences from the perspective of subjective well-being. We thus turn our attention to indicators measuring the degree of satisfaction with household income, with one's own financial situation, and with life in general. Two other aspects are also considered here, namely, the income deemed necessary to get by, and the difficulty respondents think they have in making ends meet. As previously, the impact of the variable "number of years in income poverty" is represented graphically in Fig. 2, while detailed regression models are presented in Table 2 in the "Appendix".

When we look at the impact of the number of years spent in income poverty, conclusions are rather clear: all variables directly dealing with the financial situation seem to reflect the existence of adaptive preferences and the impact is marked. Indeed, controlling for the income level in 2010 and various sociodemographic characteristics, an additional year spent in poverty increases the odds of being more satisfied with the household income by $9.3 \%$ (model 7) and with one's financial situation by $7.7 \%$ (model 8); after 5 years these figures amount to about 56 and $45 \%$ respectively. In addition, each additional year of financial deprivation reduces the odds of having more difficulties in making ends meet (model 9), namely by $10 \%$ after a year, and by $41 \%$ if the entire period is spent in income poverty; this information, combined with the fact that the logarithm of the minimum income deemed necessary to get by decreases by 0.055 (model 6) — which corresponds to a household income that goes down by $5.4 \%$ after 1 year of poverty, and by $24 \%$ after 5 years-allows us to quantify the degree to which respondents have gotten used to their financial situation. 
In contrast, the likelihood of being more satisfied with life in general (model 10) does not change at all, as the effect is statistically insignificant. The latter result is probably attributable to the fact that life satisfaction is correlated with many more life domains than just the material dimension, for instance, health (Hagerty et al. 2001; Slocum-Gori et al. 2009).

\section{Discussion}

A first point worth discussing pertains to the items used in the construction of the material deprivation indices used here. Some items appear to have an inherently subjective dimension and display patterns of adaptive preferences, notably the "ability" to save a certain amount of money each month, or the fact of being in "arrears" with payment (each item was regressed on the set of independent variables used in the models above, results not shown here for the sake of conciseness). Moreover, it seems that some items are acquired even in the face of financial difficulties, e.g., mobile phones. However, this does not appear to distort findings based on the original approach to material deprivation advocated by Townsend (1979), as already mentioned above.

Perhaps more importantly, the results observed for the PDI are really noteworthy: the fact that deprivation items are weighted according to the importance the population attributes to them appears to be decisive. This seems to imply that when a large majority of the population thinks that certain items are necessary to lead a decent life, it is more difficult for people to get used to the fact of not being able to afford these goods or services, thereby preventing, or at least slowing down, the homeostatic process. In sociological terms, when a good or service is widely perceived as necessary, it is more difficult for income-poor households to "make a virtue of necessity" (Bourdieu 1979).

Last but not least, it is important to note that the results we have presented are weighted with the transversal weights provided with the SHP database for the year 2010. However, as is well-known, low-income households have a higher propensity to drop out of the panel in longitudinal surveys (Crettaz 2012). In order to correct this attrition bias, we calculated a specific weighting scheme. On the basis of a logistic regression model, the log odds of participating in every wave between 2006 and 2010 are regressed on the logarithm of disposable equivalized income, as well as on the household size and composition. The probability of participating in each wave is estimated on this basis. Then the inverse of these estimated probabilities is calculated and multiplied by the transversal weights found in the SHP dataset. We then re-ran our regressions with these new weighting factors: the regression coefficients are hardly affected, and some are even exactly the same (results not shown), which further confirms the consistency of our results.

\section{Conclusions and Policy Implications}

Our empirical analysis demonstrates that the phenomenon of downward adaptation by individuals and households affected by income poverty concerns both indicators of material deprivation and subjective indicators related to income satisfaction and financial constraints. The bias caused by adaptation processes, however, varies considerably among 
the various measures and indicators examined within each of these two groups, and some of them, in fact, appear not to be affected at all.

Regarding deprivation measures we found not only the expected strong impact on indicators based on the "I cannot afford it" items, but also on the Eurostat indicator of not being able to afford at least three out of nine items. In contrast, the simple, unweighted sum of lacking items, i.e., the deprivation indicator originally proposed by Townsend, appears to be only weakly affected. Rather surprising is our finding that the PDI is very robust and does not show any bias due to adaptive preferences of poor people, which is very likely to be due to the weighting scheme used.

Regarding subjective poverty and well-being indicators our results point to the strong impact of adaptive preferences on the minimum income question, on satisfaction with household income, satisfaction with one's own financial situation and on the question relating to "difficulties in making ends meet". General life satisfaction, however, appears to be unaffected by poverty-related adaptation processes.

These findings suggest that subjective indicators are indeed often affected by the problem of adaptive preferences. In particular, downward adaptation due to (long-term) poverty, i.e., the fact that the poor get used to financial and material hardship, raises doubts about the suitability of subjective indicators for policy making. Unfortunately, several indicators currently used and published by Eurostat and the OECD appear to be heavily biased by downward adaptation of poverty-affected households. Subjective indicators, therefore, should be carefully examined and tested for adaptation and social comparison effects before they are used for policy making.

Our results, however, also demonstrate that subjective indicators are not generally (and not similarly) affected by downward adaptation. Regarding the possible effects of longterm poverty, we even found subjective indicators that are robust and apparently not biased. Thus, there are good methodological solutions when using subjective indicators for policy making; among them are the key measures of nonmonetary deprivation and general subjective well-being.

Our analysis has been limited to deprivation measures and to specific indicators of subjective poverty, focusing on the problem of downward adaptation due to long-term poverty of Swiss citizens. This suggests interesting avenues for future research, such as examining other indicators, including more sophisticated indices of subjective well-being and quality of life, other welfare problems or life circumstances that might be prone to adaptation and social comparison (including upward adaptation), as well as group-specific and country-specific mechanisms of adaptation.

Acknowledgments The research reported here was funded by the Swiss National Science Foundation (Grant Number 100017_143320).

\section{Appendix}

The ten regression models discussed in this article are presented in Tables 1 and 2. Table 1 corresponds to Fig. 1 above, while Table 2 corresponds to Fig. 2. 
Table 1 Impact of the number of years spent in income poverty on various indicators of material deprivation

\begin{tabular}{|c|c|c|c|c|c|}
\hline & $\begin{array}{l}\text { (1) } \\
\text { Odds of being } \\
\text { material deprived } \\
\text { due to financial } \\
\text { reasons ( } 3 \text { items or } \\
\text { more) }\end{array}$ & $\begin{array}{l}\text { (2) } \\
\text { Odds of being } \\
\text { material deprived } \\
\text { due to financial } \\
\text { reasons ( } 3 \text { items or } \\
\text { more) }\end{array}$ & $\begin{array}{l}\text { (3) } \\
\text { Odds of an } \\
\text { increased } \\
\text { number of } \\
\text { items one } \\
\text { cannot afford }\end{array}$ & $\begin{array}{l}\text { (4) } \\
\text { Odds of an } \\
\text { increased } \\
\text { number of } \\
\text { items not } \\
\text { possessed }\end{array}$ & $\begin{array}{l}\text { (5) } \\
\text { Standardized } \\
\text { proportional } \\
\text { deprivation } \\
\text { index PDI } \\
(0-100)\end{array}$ \\
\hline $\begin{array}{l}\text { Regression } \\
\text { type }\end{array}$ & Logit & Logit & Ordered logit & $\begin{array}{l}\text { Ordered } \\
\text { logit }\end{array}$ & $\begin{array}{l}\text { Weighted } \\
\text { least squares }\end{array}$ \\
\hline $\begin{array}{c}\text { Number of } \\
\text { years in } \\
\text { relative } \\
\text { poverty }\end{array}$ & 0.872 & 0.854 & 0.857 & 0.994 & 0.177 \\
\hline Log(income) & 0.464 & 0.046 & 0.050 & 0.096 & -5.790 \\
\hline Women & 1.347 & 1.655 & 1.627 & 1.409 & 1.246 \\
\hline \multicolumn{6}{|c|}{ Educational level (ref: primary) } \\
\hline Secondary & 1.483 & 1.132 & 1.150 & 0.626 & -.955 \\
\hline Tertiary & 0.902 & 0.578 & 1.040 & 0.667 & -.951 \\
\hline $\begin{array}{l}\text { Number of } \\
\text { adults in } \mathrm{HH}\end{array}$ & 1.984 & 2.437 & 2.331 & 1.564 & 0.991 \\
\hline $\begin{array}{l}\text { Number of } \\
\text { children in } \\
\text { HH }\end{array}$ & 1.657 & 1.428 & 1.567 & 1.153 & 0.122 \\
\hline \multicolumn{6}{|c|}{ Age (ref: 46-60 years old) } \\
\hline $\begin{array}{l}18-30 \text { years } \\
\text { old }\end{array}$ & 0.603 & 0.538 & 1.683 & 1.183 & -2.379 \\
\hline $\begin{array}{l}31-45 \text { years } \\
\text { old }\end{array}$ & 0.425 & 0.302 & 0.865 & 0.855 & -1.298 \\
\hline $\begin{array}{l}61-75 \text { years } \\
\text { old }\end{array}$ & 0.731 & 0.430 & 0.913 & 0.688 & -1.581 \\
\hline 76 and older & 0.117 & 0.259 & 0.712 & 1.210 & -3.174 \\
\hline \multicolumn{6}{|c|}{ Employment status (ref: in work) } \\
\hline Unemployed & 0.444 & 2.567 & 3.171 & 3.683 & 4.978 \\
\hline Inactive & 0.531 & 0.720 & 0.760 & 1.219 & -.314 \\
\hline $\begin{array}{l}\text { Number of } \\
\text { lacking items }\end{array}$ & 5.825 & & & & \\
\hline $\begin{array}{l}\text { Number of } \\
\text { cases }\end{array}$ & 1,288 & 1,288 & 1,306 & 1,306 & 1,306 \\
\hline $\begin{array}{l}\text { Nagelkerke's } \\
\text { pseudo-R }{ }^{2}\end{array}$ & 0.592 & 0.183 & 0.228 & 0.279 & \\
\hline $\mathrm{R}^{2}$ & & & & & 0.098 \\
\hline
\end{tabular}

Income poverty defined as below $60 \%$ of the median of equivalized disposable household income. Model 1-4 contain odds ratios, model 5 contains regression coefficients. All effects are statistically significant Source: Swiss Household Panel 2006-2010, authors' calculations 
Table 2 Impact of the number of years spent in income poverty on various subjective indicators related to the income satisfaction and on the overall level of satisfaction

\begin{tabular}{|c|c|c|c|c|c|}
\hline & $\begin{array}{l}\text { (1) } \\
\text { Logarithm of } \\
\text { the answer to } \\
\text { the minimum } \\
\text { income } \\
\text { question }\end{array}$ & $\begin{array}{l}\text { (2) } \\
\text { Odds of having } \\
\text { an increased } \\
\text { level of } \\
\text { satisfaction } \\
\text { with HH } \\
\text { income }\end{array}$ & $\begin{array}{l}\text { (3) } \\
\text { Odds of having an } \\
\text { increased level of } \\
\text { satisfaction wiht } \\
\text { one's own financial } \\
\text { situation }\end{array}$ & $\begin{array}{l}\text { (4) } \\
\text { Odds of } \\
\text { having more } \\
\text { difficulties } \\
\text { in making } \\
\text { ends meet }\end{array}$ & $\begin{array}{l}\text { (5) } \\
\text { Odds of having } \\
\text { an increased } \\
\text { level of } \\
\text { satisfaction with } \\
\text { life in general }\end{array}$ \\
\hline $\begin{array}{l}\text { Regression } \\
\text { type }\end{array}$ & $\begin{array}{l}\text { Ordinary } \\
\text { least square }\end{array}$ & Ordered logit & Ordered logit & $\begin{array}{l}\text { Ordered } \\
\text { logit }\end{array}$ & Ordered logit \\
\hline $\begin{array}{l}\text { Number of } \\
\text { years in } \\
\text { relative } \\
\text { poverty }\end{array}$ & -0.055 & 1.093 & 1.077 & 0.900 & 1.002 \\
\hline Ln(income) & 0.359 & 6.546 & 5.751 & 0.101 & 1.673 \\
\hline Women & -0.014 & 1.092 & 1.245 & 1.007 & 1.165 \\
\hline \multicolumn{6}{|c|}{ Educational level (ref: primary) } \\
\hline Secondary & 0.146 & 0.699 & 0.724 & 1.488 & 0.746 \\
\hline Tertiary & 0.205 & 0.902 & 0.799 & 1.103 & 0.890 \\
\hline $\begin{array}{l}\text { Number of } \\
\text { adults in } \mathrm{HH}\end{array}$ & 0.052 & 0.597 & 0.585 & 1.932 & 1.111 \\
\hline $\begin{array}{l}\text { Number of } \\
\text { children in } \\
\mathrm{HH}\end{array}$ & 0.078 & 0.841 & 0.931 & 1.399 & 1.009 \\
\hline \multicolumn{6}{|c|}{ Age (ref: 46-60 years old) } \\
\hline $\begin{array}{l}\text { 18-30 years } \\
\text { old }\end{array}$ & -0.195 & 0.361 & 0.459 & 1.919 & 0.433 \\
\hline $\begin{array}{l}31-45 \text { years } \\
\text { old }\end{array}$ & -0.048 & 0.937 & 0.908 & 1.168 & 0.972 \\
\hline $\begin{array}{l}61-75 \text { years } \\
\text { old }\end{array}$ & -0.060 & 1.397 & 1.779 & 0.892 & 1.403 \\
\hline 76 and older & -0.060 & 1.787 & 2.754 & 0.668 & 1.277 \\
\hline \multicolumn{6}{|c|}{ Employment status (ref: in work) } \\
\hline Unemployed & -0.058 & 0.129 & 0.122 & 2.744 & 0.171 \\
\hline Inactive & 0.091 & 1.356 & 1.372 & 0.715 & 1.244 \\
\hline $\begin{array}{l}\text { Number of } \\
\text { cases }\end{array}$ & 1,294 & 1,306 & 1,304 & 1,306 & 1,305 \\
\hline $\begin{array}{l}\text { Nagelkerke's } \\
\text { pseudo- } R^{2}\end{array}$ & & 0.157 & 0.148 & 0.196 & 0.054 \\
\hline $\mathrm{R}^{2}$ & 0.408 & & & & \\
\hline
\end{tabular}

Income poverty defined as below $60 \%$ of the median of equivalized disposable household income. Model 1 contains regression coefficients, while models 2-5 contain odds ratios. All effects are statistically significant, except for the one marked in grey

Source: Swiss Household Panel 2006-2010, authors' calculations 


\section{References}

Boarini, R., \& Mira d'Ercole, M. (2006). Measures of material deprivation in OECD Countries. OECD Social, Employment and Migration Working Papers. Paris: OECD Publishing.

Bourdieu, P. (1979). La distinction: critique sociale du jugement. Paris: Ed. de Minuit.

Brickman, P., \& Campbell, D. T. (1971). Hedonic relativism and planning the good society. In M. H. Appley (Ed.), Adaptation-level theory (pp. 287-305). New York: Academic Press.

Crettaz, E. (2011). Fighting working poverty in postindustrial economies: Causes trade-offs and policy solutions. Cheltenham and Northampton, MA: Edward Elgar Publishing.

Crettaz, E. (2012). Social indicators and adaptive preferences: What is the impact of income poverty on indicators of material deprivation and on the minimum income question? Swiss Journal of Sociology, $38(3), 421-440$.

Diener, E., Lucas, R. E., \& Napa Scollon, C. (2006). Beyond the hedonic treadmill. Revising the adaption theory of well-being. American Psychologist, 616(4), 305-314.

Easterlin, R. A. (1974). Does economic growth improve the human lot? Some empirical evidence. In P. A. David \& M. W. Reder (Eds.), Nations and households in economic growth: Essays in honor of moses abramovitz (pp. 89-125). New York: Academic Press.

Festinger, L. (1954). A theory of social comparison processes. Human Relations, 7, 117-140.

Gazareth, P., \& Suter, C. (2010). Privation et risque d'appauvrissement en Suisse, 1999-2007. Swiss Journal of Sociology, 36(2), 213-234.

Hagerty, M. R., Cummins, R. A., Ferriss, A. L., Land, K., Michalos, A. C., Peterson, M., et al. (2001). Quality of life indexes for national policy: Review and agenda for research. Social Indicators Research, 55(1), 1-96.

Halleröd, B. (1994). A new approach to the direct consensual measurement of poverty. Social Policy Research Centre discussion paper (Vol. 50).

Halleröd, B. (1995). The truly poor: Direct and indirect consensual measurement of poverty in Sweden. Journal of European Social Policy, 5(2), 111-129.

Halleröd, B. (2006). Sour grapes: Relative deprivation, adaptive preferences and the measurement of poverty. Journal of Social Policy, 35, 371-390.

Lucas, R. E., Clark, A., Georgellis, Y., \& Diener, E. (2003). Reexamining adaption and the set point model of happiness: Reactions to changes in marital status. Journal of Personality and Social Psychology, 84, $527-539$

Mack, J., \& Lansley, S. (1985). Poor britain. London: George Allen and Unwin Ltd.

Nolan, B., \& Whelan, C. T. (2007). On the multidimensionality of poverty and social exclusion. In J. Micklewright \& S. P. Jenkins (Eds.), Poverty and inequality: New directions (pp. 146-165). Oxford: Oxford University Press.

Nolan, B., \& Whelan, C. T. (2010). Using non-monetary deprivation indicators to analyze poverty and social exclusion: Lessons from Europe? Journal of Policy Analysis and Management, 29(2), 305-325.

OECD. (2008). Growing unequal? Income distribution and poverty in OECD countries. Paris: OECD.

Runciman, W. G. (1966). Relative deprivation and social justice. London: Routledge \& Kegan Paul.

Sen, A. (1984). Resources, values and development. Oxford: Blackwell.

Slocum-Gori, S. L., Zumbo, B. D., Michalos, A. C., \& Diener, E. (2009). A note on the dimensionality of quality of life scales: An illustration with the satisfaction with life Scale (SWLS). Social Indicators Research, 92(3), 489-496. doi:10.1007/s11205-008-9303-y.

Stiglitz, J. E., Sen, A., \& Fitoussi, J. P. (2009). Report by the commission on the measurement of economic Performance and social progress.

Suter, C., \& Iglesias, K. (2005). Relative deprivation and well-being. In H. Kriesi, P. Farago, M. Kohli, \& M. Zarin-Nejadan (Eds.), Contemporary Switzerland. Revisiting the special case (pp. 9-37). Houndmills: Palgrave Macmillan.

Suter, C., \& Paris, D. (2002). Ungleichheit und deprivation: Die schweiz im drei-länder-vergleich. Swiss Journal of Sociology, 28(2), 217-240.

Swiss Federal Statistical Office. (2012). Armut in der schweiz: konzepte, resultate und methoden. Ergebnisse auf der basis von SILC 2008 bis 2010. Neuchâtel: SFSO.

Townsend, P. (1979). Poverty in the United Kingdom: A survey of household resources and standards of living. London: Penguin.

Van Praag, B., Goedhart, T., \& Kapteyn, A. (1980). The poverty line-A pilot survey in Europe. Review of Economics and Statistics, 62(3), 461-465. 